\title{
XXXIII Congresso Brasileiro de Radiologia - Rio de Janeiro/2004
}

Alair Augusto Sarmet M.D. dos Santos

Presidente da Sociedade Brasileira de Radiologia

Acabamos de realizar na cidade do Rio de Janeiro, entre 12 e 14 de novembro de 2004, o XXXIII Congresso Brasileiro de Radiologia, que não era realizado na Cidade Maravilhosa há mais de 12 anos.

Foi um sucesso completo, especialmente a parte científica, que foi extremamente elogiada por todos os participantes. Tivemos uma programação de altíssimo nível, sendo contempladas todas as áreas da Radiologia, inclusive Informática (PACS) e Gestão em Radiologia, contando ainda como uma sala destinada aos Técnicos e outra ao Curso AVR (Assistência à Vida em Radiologia). Para tanto, tivemos a colaboração de diversos radiologistas do Rio de Janeiro e do Brasil, que fizeram parte das Comissões Científicas e Organizadora, notadamente os Drs. Paulo Villar e Pedro Daltro.

Contamos com a participação de 11 professores estrangeiros: Alan Daneman (Pediatria), Alfredo Weber (Cabeça e Pescoço), Barry Alan Siegel (PET CT Scan), Bruce McClennan (Urologia), Bruno Fornage (Ginecologia e Obstetrícia), Conceição Sanches (Pediatria), Donald Resnick (Musculoesquelético), George S. Bisset (US e TC), Nestor Müller (Tórax), Richard Semelka (Abdome) e Scott Atlas (Neurorradiologia). Exceto Alan Daneman e Nestor Müller, que eram do Canadá, e Conceição Sanches, de Portugal, todos os demais eram dos EUA. Os Drs. Daneman, Weber e Resnick foram homenageados na cerimônia de abertura, com o título de Membros Honorários do CBR, pelos relevantes serviços prestados divulgando o Ensino da Radiologia entre os brasileiros, pois receberam inúmeros colegas em seus serviços, ao longo dos anos.

Tivemos ainda a participação maciça de radiologistas de todo o Brasil, ministrando aulas de excelente nível e comprovando a qualidade da Radiologia em nosso país.

Outro ponto forte deste Congresso foi a apresentação de temas livres e pôsteres. Foram encaminhados para seleção cerca de 525 trabalhos científicos, sendo selecionados 326 , após análise criteriosa da Comissão Julgadora. Foram apresentados 33 temas livres (apresentação oral), 265 pôsteres e 28 painéis comentados. Esta última categoria engloba os melhores pôsteres que passaram por uma apresentação oral com comentários de julgadores, durante o Congresso, em horário pré-estabelecido. Esta atividade foi muito interessante por propiciar maior contato entre os autores e a Comissão Julgadora, sendo avaliados por pelo menos dois radiologistas de outros serviços, que na troca de informações não só acrescentaram dados e experiências, como serviram de estímulo para os apresentadores, em geral radiologistas mais novos, muitas vezes residentes.

Todos estes trabalhos tiveram seus resumos publicados pela Radiologia Brasileira, em número suplementar, que foi distribuído durante o Congresso.

Finalmente, devemos referenciar as sessões de Interpretação de Imagens, que também tiveram inovações. Foram realizadas duas sessões, uma com radiologistas experientes e conhecidos de todos, por darem palestras em vários eventos no país, sendo referências 
em suas áreas. Este grupo foi formado pelos Drs. Silvio Litvin (PE), Henrique Lederman (SP), Vanildo Ozelame (SC) e Douglas Racy (SP), sendo coordenados pelo Dr. Paulo Villar (RJ). A segunda sessão de Interpretação de Imagens foi realizada com a participação de radiologistas mais jovens, sendo coordenados pelo Dr. Mauro Esteves (RJ). Fizeram parte do grupo os Drs. Luiz Felipe Nobre (SC), Márcio Vieira de Almeida (RJ), Luiz Fernando A. Mendes (RJ) e Nelson Pés F. Diniz Ferreira (SP). Em ambas as sessões os casos foram apresentados e debatidos seguindo um raciocínio diagnóstico lógico, sendo discutidos os principais sinais radiológicos e apontados os diagnósticos diferenciais pertinentes.

Finalmente, vale informar que foi lançado, durante a Assembléia Geral do CBR, o Livro de Radiologia do Aparelho Respiratório da Sociedade Brasileira de Radiologia, referente ao respectivo módulo ministrado no Curso de Radiologia Prof. Abércio Arantes Pereira, como uma forma de homenagear este grande mestre da Radiologia Brasileira, recentemente falecido, e mostrar a qualidade das nossas aulas, pois cada capítulo foi escrito baseado na respectiva aula.

Acreditamos que conseguimos atingir todos os objetivos propostos, especialmente em trazer e divulgar o conhecimento científico, buscando discussões e novas maneiras de interação dos diversos métodos de imagem e entre todos os participantes, com ampla participação nacional e internacional, promovendo um clima extremamente agradável e de integração, tarefas estas imprescindíveis para um Congresso Brasileiro de sucesso, como foi este, no Rio de Janeiro. 